\title{
Karbon Nanotüp Katkılı Levha Kalıplama Pestilinin AC Elektriksel İletkenliğinin ve Dielektrik Özelliklerinin İncelenmesi
}

\author{
Aykut ILGAZ $^{1 *}$, Deniz PERINN ${ }^{2}$ \\ ${ }^{1}$ Balıkesir Üniversitesi, Fen Edebiyat Fakültesi, Fizik Bölümü, Balıkesir, Türkiye \\ ${ }^{2}$ Issbir Elektrik A.S., Çayırhisar Mh. Yeni İzmir Cd. No:39, Balıkesir, Türkiye \\ (ORCID: 0000-0002-9632-0281) (ORCID: 0000-0003-3697-3499)
}

\begin{abstract}
Öz
Cam elyaf takviyeli ve doymamış polyester bazlı polimer kompozit malzemelerin iletkenlik ve dielektrik özelliklerini kontrol etmek için son yıllarda yaygın biçimde kullanılan karbon nanotüpler, yüksek potansiyelli materyallerdir. $\mathrm{Bu}$ çalışmada doymamış polyester bazlı standart levha kalıplama pestili (Sheet moulding compound/SMC) ve yüzde 1,2 oranında tek duvarlı karbon nanotüp (TDKN) ile katkılanmış malzeme için, kritik çalışma parametreleri olan AC elektriksel iletkenliği, dielektrik sabiti, dielektrik kayıp faktörü ve dielektrik dağılım faktörü (kayıp tanjant) değerleri karşılaştırmalı olarak analiz edilmiştir. $50 \mathrm{~Hz}$ ve $100 \mathrm{kHz}$ frekans aralığında yapılan ölçümlerden elde edilen sonuçlar, karbon nanotüp katkısının yalıtkan olan malzemenin direncini önemli ölçüde azalttığını ve malzemenin AC iletkenliğini önemli ölçüde arttırdığını ortaya koymuştur. Aynı zamanda katkılı numune için iletkenliğin frekans değişiminden neredeyse bağımsız olduğu da sonuçlardan görülmektedir. Bununla birlikte dielektrik özelliklerin farklı polarizasyon etkileri nedeniyle frekansa bağlı davranış sergilediği ve artan frekans değerlerinde azalma eğilimi gösterdikleri bulunmuştur.
\end{abstract}

Anahtar kelimeler: Karbon Nanotüp, Levha Kalıplama Pestili, AC İletkenlik, Dielektrik Sabiti.

\section{AC Electrical Conductivity and Dielectric Properties of Carbon Nanotube Reinforced Sheet Moulding Compound}

\begin{abstract}
Carbon nanotubes are high potential materials that have been widely used in recent years to control the conductivity and dielectric properties of glass fiber reinforced and unsaturated polyester-based polymer composite materials. AC electrical conductivity, dielectric constant, dielectric loss factor and dielectric dispersion factor (loss tangent) which are critical operating parameters were analyzed comparatively for the unsaturated polyester based standard sheet molding compound and its 1,2 percent single-walled carbon nanotube (SWCNT) reinforced version in this study. The results obtained from the measurements made in the frequency range of $50 \mathrm{~Hz}$ and $100 \mathrm{kHz}$ revealed that the carbon nanotube addition significantly reduced the resistance of the insulating material and remarkably increased the AC conductivity of the material. It can also be seen from the results that the conductivity is almost independent of frequency variation. However, it has been found that dielectric properties of materials exhibit frequency-dependent behavior due to different polarization effects and tend to decrease at increasing frequency values.
\end{abstract}

Keywords: Carbon Nanotube, Sheet Molding Compound, AC Conductivity, Dielectric Constant.

\section{Giriş}

Geleneksel cam elyaf takviyeli polimer (CETP) kompozitlerde katk1 maddesi olarak karbon nanotüplerin (KNT) kullanımına ilişkin çalışmaların sayısı son yirmi yılda önemli ölçüde artmıştır [14]. Polimer kompozitlere düşük konsantrasyonlarda eklenen karbon nanotüplerin malzemenin elektriksel iletkenliklerini olağanüstü derecede arttırdığ 1 ve hatta iletkenliklerinin yarı iletken

*Sorumlu yazar: aykutilgaz@balikesir.edu.tr

Geliş Tarihi: 30.11.2020, Kabul Tarihi: 21.03.2021 
seviyelerine ulaştığı literatürde yapılan çalışmalardan iyi bilinmektedir [5-7]. Yüksek en/boy oranı, mekanik dayanımı, üstün elektriksel özelliklere sahip karbon nanotüplerin kompozit malzemeye eklenmesi, elektromanyetik radyasyon kalkanı gibi uygulamalarda yalıtkan doğaya sahip polimerin iletkenlik özelliklerini iyileştirmek ve kontrol edebilmek adına büyük avantajlar sağlamaktadır [8].

Karbon nanotüp ile güçlendirilmiş kompozitlerde elektriksel iletkenliği tanımlayan temel teori süzülme teorisidir [9,10]. Düşük konsantrasyonlu katkılı karbon nanotüpler, matristeki kümeler halinde rastgele dağıtılır. Bu durumda, direnç azalmasına rağmen kompozit, yalıtım özelliklerini korumaya devam eder. Katkı maddesinin konsantrasyonu artmaya başladığında, izole edilmiş kümeler yavaş yavaş büyür. Sonunda, matris içinde birbirine bağlı bölgeler oluşturulur. Polimerin yalıtım durumdan iletim durumuna geçtiği bu noktaya süzülme (perkolasyon) eşiği veya kritik konsantrasyon denir. Elektriksel süzülme eşiğinin değeri, polimer matrisine, katk1 maddesinin yoğunluğuna ve kompozitin hazırlama yöntemine bağlı olarak değişir [11].

$\mathrm{Bu}$ çalı̧̧mada, doymamış polyester bazlı levha kalıplama pestili (SMC-Sheet Moulding Compound) malzemeler standart ve tek duvarlı karbon nanotüp (TDKN) katkılı biçimde üretilmiştir. Üretilen malzemelerin AC iletkenlik davranışları ve dielektrik özellikleri frekansa bağlı olarak incelenmiş ve deneylerden elde edilen veriler kullanılarak karşılaştırmalı olarak analiz edilmiştir. Teorik fitler sayesinde ise ölçüm yapılamayan frekans aralıklarında, malzemelerin karakteristikleri ortaya konulmuş ve yapılan ölçümlerin doğruluğunu test eden düzeltilmiş belirleme katsayıları hesaplanarak analizlere dahil edilmiştir.

\section{Materyal ve Metot}

\subsection{Materyal Üretimi}

Sıcak pres üretim metodu yoluyla $\% 26$ oranında doymamış polyester, $\% 11$ oranında dolgu maddesi, $\% 1.8$ oranında stiren, $\% 0.5$ oranında peroksit, $\% 1.8$ oranında çinko sülfit, $\% 33$ oranında kalsiyum karbonat, \%0.9 oranında kıvam verici madde ve \%25 oranında cam elyaf içeren iki adet SMC malzeme hazırlanmıştır. İlki standart prosedürle hazırlanırken ikinci numuneye ek olarak ağırlıkça \% 1.2 oranında tek duvarlı karbon nanotüp katkılanmıştır.

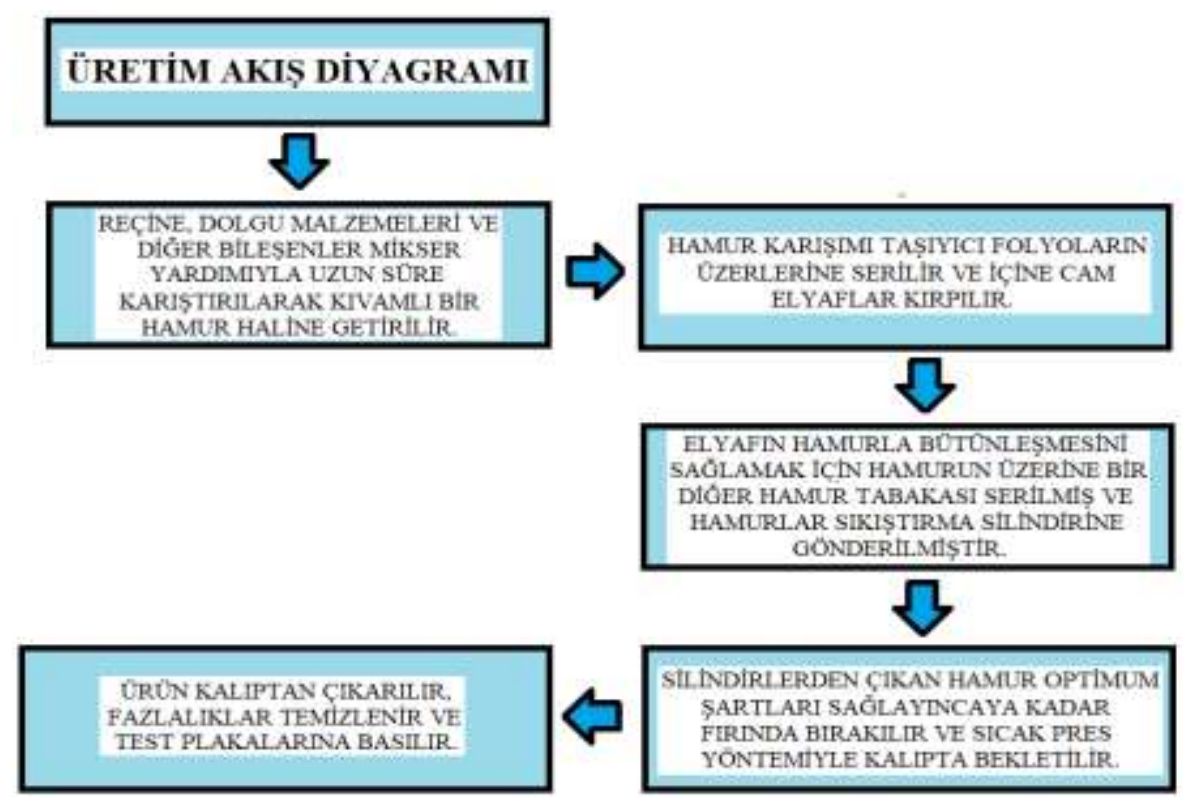

Şekil 1. Numunelerin üretim akış diyagramı

Üretilen cam elyaf katkılı numunelerin üretim akış diyagramı Şekil 1'de görülmektedir. Numunelerin üretim sürecinde ilk olarak polyester reçine ve diğer katkı malzemeleri malzeme içinde meydana gelebilecek topaklanma gibi heterojen durumları engellemek ve tüm bileşenlerin entegrasyonu amacıyla mikserlerde devamlı karıştırılarak kıvamlı bir hamur elde edilmiştir. Hamur daha sonra polietilen taşıyıcı filmlerin üzerlerine serilmiştir. Burada hamura cam elyaf takviyesi yapılmış olup cam 
elyafların mümkün olduğunca hamurun içine homojen dağılmasına özen gösterilmiştir. Hamura kırpılan cam elyafın diğer bileşenlerle uyumunun dahi iyi olması için üzerine yeni bir kat hamur daha serilmiştir. Hava boşluklarını yok etmek için hamur taşıyıcı filmler arasında sıkıştırılmış ve firına gönderilerek sıcak pres uygulanmıştır. Malzemenin olgunlaşması için en az 2 gün kadar firında bırakılmış ve sıcak pres yöntemiyle $135-175^{\circ} \mathrm{C}$ sıcaklıları arasında 1sıtılmış olan kalıpta bekletilmiştir. Piyasadaki CETP malzemelerin viskozite değeri, 1sıtma sıcaklığı ve süresine bağlı olarak değişkenlikler göstermektedir. $\mathrm{Bu}$ çalışma için üretilen numunenin minimum viskozite değeri $17000 \mathrm{~Pa}$.s ve maksimum değeri 21100 Pa.s olarak ölçülmüştür. $\quad 160 \mathrm{~kg} / \mathrm{cm}^{2}$ kalıp baskı basıncında tutulan malzemenin her milimetresi için 2,5 dakika kalıplama süresi uygulanmıştır. Daha sonra ürün kalıptan çıkarılarak fazlalıkları tıraşlanmış ve $250 \mathrm{~mm}$ x $150 \mathrm{~mm}$ x $3 \mathrm{~mm}$ 'lik örnekler test plakalarına basılarak üretilmiştir. Şekil 2'de görüldüğü gibi numuneler, test plakalarından $20 \mathrm{~cm}$ uzunluğunda ve $1,5 \mathrm{~cm}$ genişliğinde kesilerek ölçümler alınmıştır.

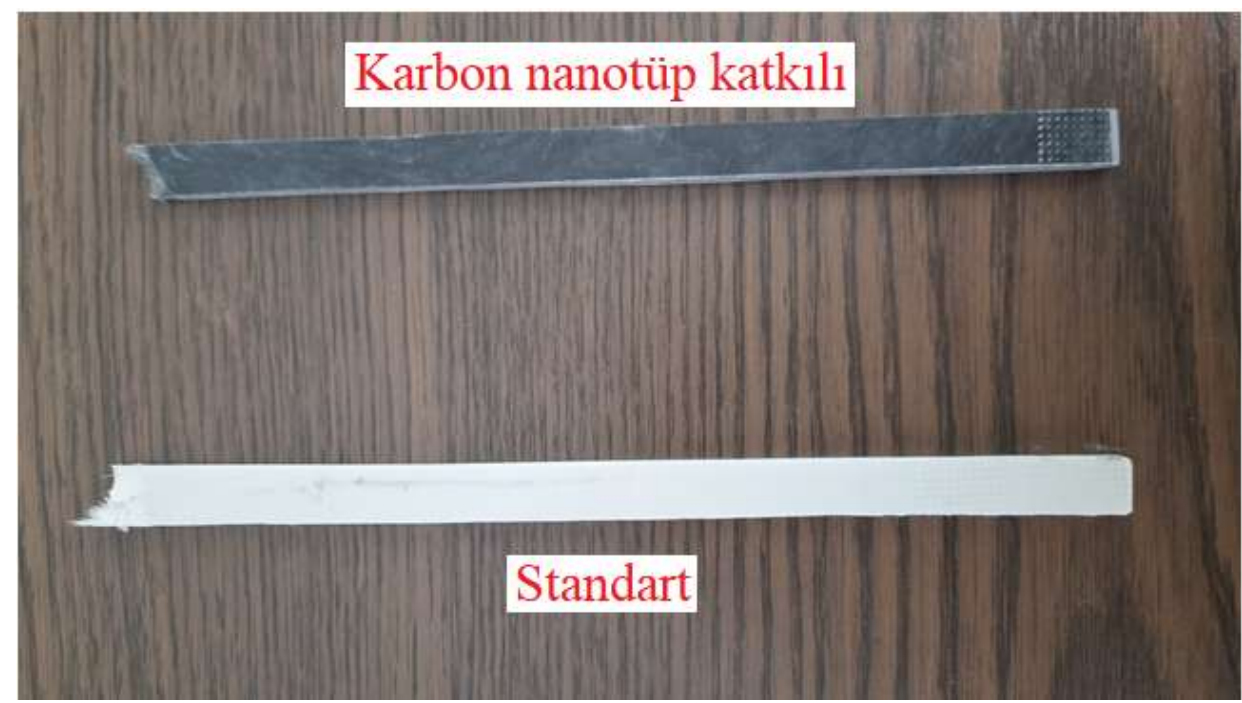

Şekil 2. Ölçümlerde kullanılan standart ve karbon nanotüp katkılı numuneler.

\subsection{Metot}

Her iki yüzeyi gümüş macun ile kaplanan kompozit filmlerin elektriksel tepkileri, $50 \mathrm{~Hz}$ ila $100 \mathrm{kHz}$ frekans aralığında bir empedans spektrometresi (Zurich Technologies, MFIA Impedance Analyzer) yardımıyla analiz edilmiştir. İletkenliğin frekansa bağlı değişimini incelemek için sıcaklık sabit tutulmuş ve ölçümler oda sıcaklığında tamamlanmıştır. CETP kompozitlerin AC iletkenliklerini $\left(\sigma_{\mathrm{AC}}\right)$ ifade etmek için şu eşitlik kullanılmıştır [12]:

$$
\sigma_{A C}=\sigma_{D C}+A \cdot f^{5}
$$

$\sigma_{\mathrm{DC}}$ doğru akım iletkenliği, f frekans, A ve $\mathrm{n}$ sabitlerdir. Doğru ve alternatif akım iletkenlikleri, Siemens/metre $(\mathrm{S} / \mathrm{m})$ biriminde hesaplanmış olup frekansın birimi ise Hertz $(\mathrm{Hz})$ olarak alınmıştır. Malzemenin dielektrik özelliklerini analiz etmek için ise ilk olarak numunelerin sığaları ölçülmüştür. $\mathrm{Bu}$ ölçümler için paralel plakalı kondansatör elde etmek amacıyla iki metal plaka arasına $20 \mathrm{~mm}$ boyunda, $5 \mathrm{~mm}$ genişliğinde ve $4 \mathrm{~mm}$ kalınlığında olan numuneler yerleştirilmiştir. Metal plakaların yüzeyleri kutuplanma etkisini en aza indirmek için gümüş boya ile işleme tabi tutulmuştur. Oda sıcaklığında ve değişen frekans değerlerinde yapılan bu sığa ölçümleri Keysight U1733C LCR metre kullanılarak doğrudan gerçekleştirilmiştir. Numunenin boyutlarını kullanarak kompozit malzemelerin dielektrik sabitleri aşağıdaki eşitlik ile hesaplanmıştır [7].

$$
\varepsilon^{\prime}=C \cdot \frac{L}{\varepsilon_{o} A}
$$

Denklemde C ölçülen sığa değeri, L plakalar arası uzaklık, $\varepsilon_{o}$ boşluğun geçirgenlik katsayısı, A plaka alanıdır. Ölçülen sığa değerinin birimi Farad (F), plakalar arası uzaklığın birimi metre, boşluğun 
geçirgenlik katsayısı birimi Farad/metre $(\mathrm{F} / \mathrm{m})$ ve plaka alanı birimi $\mathrm{m}^{2}$ olarak alınmıştır. Dielektrik kayılar malzemenin zaman içinde isınmasına neden olarak performansını olumsuz etkileyen parametrelerdendir. Dielektrik kayıp faktörü malzemenin elektrik alandan kazandığı enerjinin 1S1 enerjisine dönüşme oranı olup şu şekilde hesaplanır [13].

$$
\varepsilon^{\prime \prime}=\frac{L}{2 \pi R A f \varepsilon_{o}}
$$

Burada R elektriksel direnç olup birimi Ohm $(\Omega)$ dur. Dielektrik dağılma faktörü veya kayıp tanjantı ise dielektrik kayıplardan dolayı elektromanyetik enerjinin ne kadarının 1sı enerjisine dönüştügünü gösteren bir parametre olup dielektrik kayıp faktörünün dielektrik sabitine oranıdır [7].

$$
\operatorname{Tan} \delta=\frac{\varepsilon^{\prime \prime}}{\varepsilon^{\prime}}
$$

\section{Bulgular ve Tartışma}

\subsection{AC İletkenlik}

Şekil 3, katkısız standart ve karbon nanotüp katkılı numunelerin alternatif akım iletkenliklerini $50 \mathrm{~Hz}-$ $100 \mathrm{kHz}$ frekans aralığında göstermektedir. Standart numunenin iletkenliği frekans ile lineer bir davranış sergilerken, iletkenliğinin de belirli bir seviyede kaldığ 1 görülmektedir. Bununla birlikte TDKN ilave edilen malzemenin AC iletkenliğinin neredeyse frekanstan bağımsız olup yaklaşık olarak $10^{-2} \mathrm{~S} / \mathrm{m}$ değeri aldığı ortaya konulmuştur. Yariiletkenlerin iletkenlik seviyesi olan bu değer, kritik süzülme eşiğinin aşıldığını ve karbon nanotüplerin malzeme içinde iletkenlik ağı oluşturduklarını göstermektedir [14].

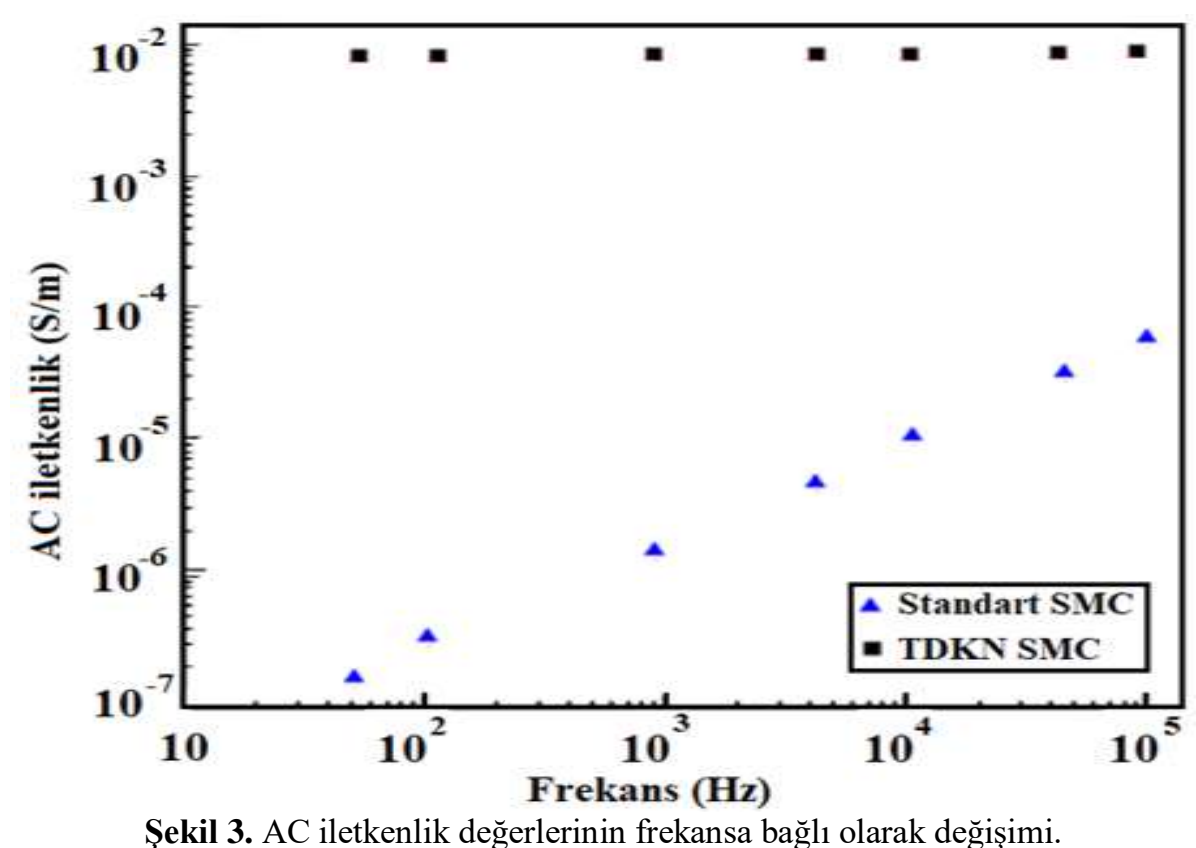

\subsection{Dielektrik Özellikler}

Şekil 4'de standart ve TDKN eklenmiş numunelerin dielektrik sabitlerinin frekans ile değişimi verilmektedir. Semboller deneysel sonuçlardan elde edilen değerleri gösterirken çizgiler yapılan teorik fiti göstermektedir. Oda sıcaklığında, $50 \mathrm{~Hz}$ ve $100 \mathrm{kHz}$ frekans aralığında gerçekleşen ölçümlerde düşük frekans değerlerinde malzemelerin dielektrik sabitlerinin daha büyük olduğu görülmektedir. Bunun nedeni düşük frekans değerlerinde etkin olan ara yüzey, atomik ve elektronik polarizasyonların varlığı olarak açıklanabilir. Atomik ve elektronik polarizasyonlar ani gelişen etkileşimler olup dielektrik 
sabitinin frekansa bağımlılığını önemli biçimde etkilemezken ara yüzey polarizasyonunun etkisi fazla olup özellikle düşük frekanslarda dielektrik özellikleri en çok etkileyen mekanizmadır $[15,16]$. Artan frekanslarda ise polarizasyon etkilerinin azalmasıyla numunelerin dielektrik sabitlerinin azaldığ görülmektedir. Tüm frekans değerlerinde TDKN katkılı numunenin dielektrik sabitleri standart malzemeye oranla daha düşüktür.

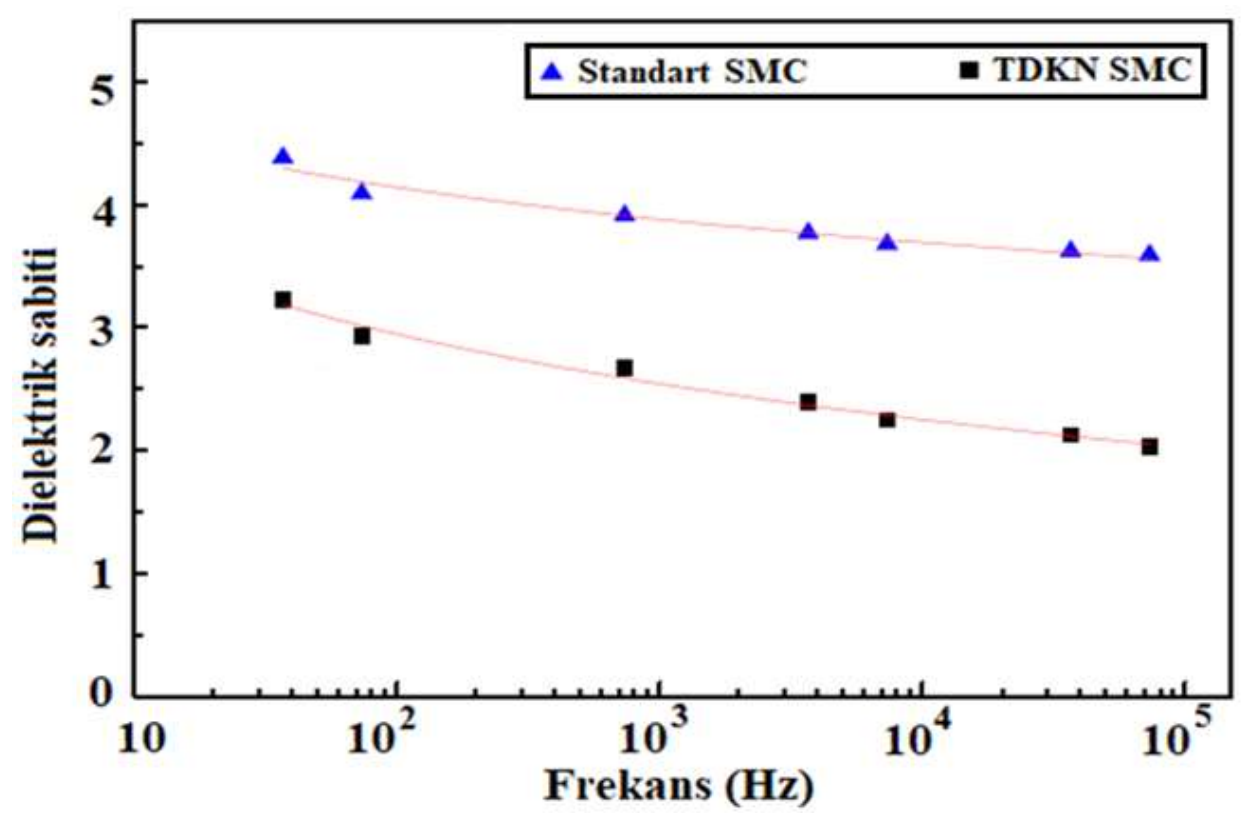

Şekil 4. Dielektrik sabitlerinin frekansa bağlı olarak değişimi.

Karbon nanotüpler, yariletken veya iletken doğaya sahip parçacıklar olmaları nedeniyle malzeme içine katkılandıkları zaman süzülme eşiği denilen kritik katkılama konsantrasyonunu aştıklarında malzemeyi iletken haline getirirler [9, 10, 17]. Bununla birlikte, karbon nanotüpler kümeler halinde toplanmaya meyilli parçacıklar olduklarından düşük frekanslarda matris içerisinde belirli bölgelerde dağılım gösterirler. Bu durum da, yüksek frekanslara nazaran düşük frekanslarda karbon nanotüp katkılı numunenin dielektrik sabitini arttıran neden olarak sunulabilir.

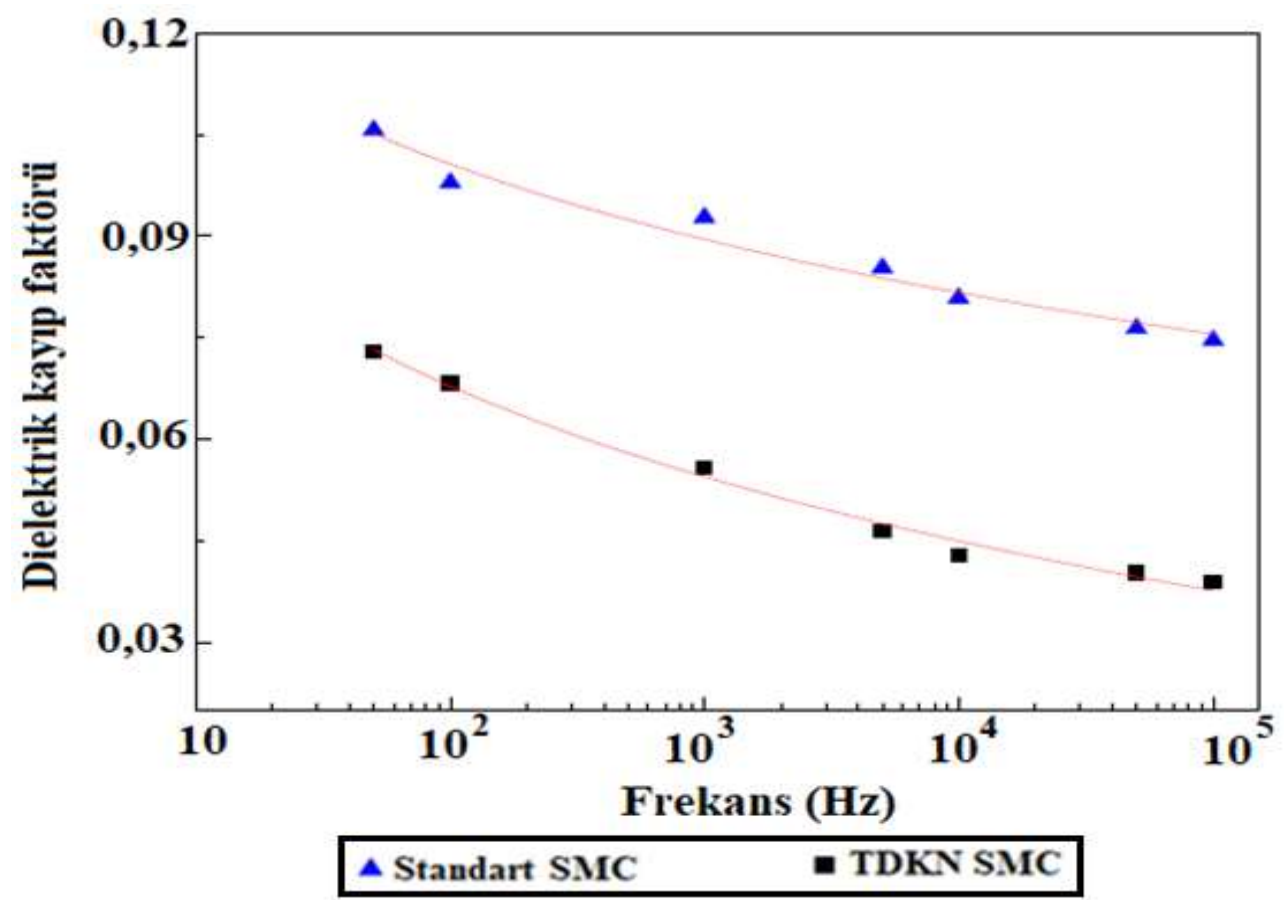

Şekil 5. Dielektrik kayıp faktörünün frekans ile değişimi. 
Malzemelerin dielektrik kayıp faktörlerinin frekans ile değişimi ise Şekil 5'de verilmektedir. Malzemenin kristal örgüsüne ve içyapısına bağlı olan dielektrik kayıpların en çok standart numunede yaşandığı görülmektedir. Gözeneklilik, mikro çatlaklar, düşük kimyasal uyum, vb. nedenlerle oluşan dielektrik kayıplar, malzeme içerisinde 1sı merkezleri gibi davranarak termal gerilimi indüklerler. Bunun sonucunda malzeme içine giren enerjinin bir kısmı 1sı enerjisi şeklinde harcanarak malzemenin 1sınmasına neden olur. Karbon nanotüpler, malzeme içindeki iletim kayıplarını azaltarak malzemeyi en verimli hale getirmiş ve karbon nanotüplü malzeme diğer numuneye göre daha az 1sınmıştır.

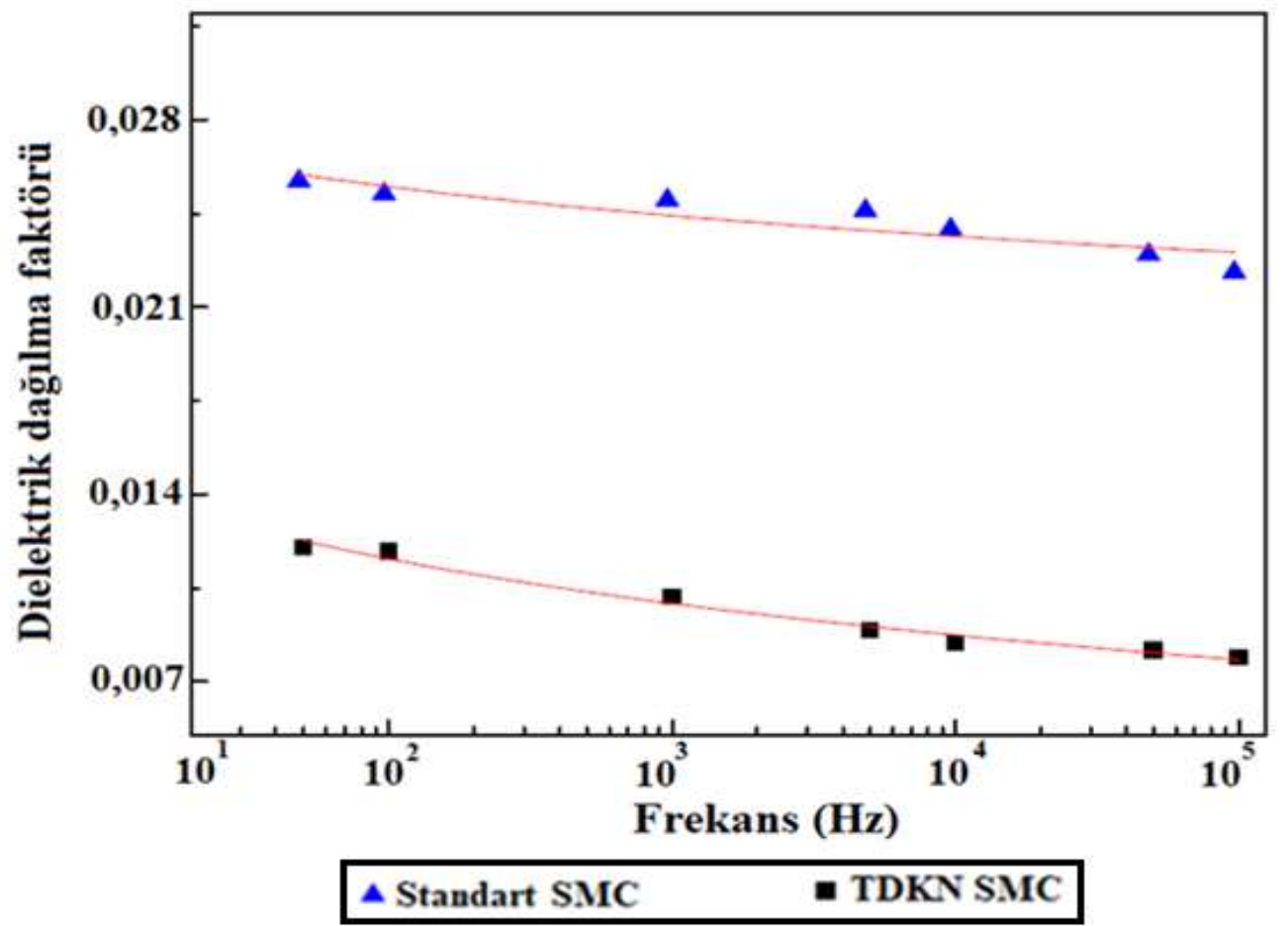

Şekil 6. Dielektrik dağılma faktörünün frekans ile değişimi.

Şekil 6'de dielektrik dağılma faktörü diğer deyişle kayıp tanjant değerlerinin frekansa bağlı değişimi gösterilmektedir. Kayıp tanjant değerleri, kayıp faktörü ile benzer biçimde davranış sergileyerek frekans ile ters orantılı biçimde değişir. Her iki dielektrik özellikteki bu azalma yüksek frekanslara gidildikçe polarizasyonların etkilerini yitirmesi ile açıklanabilir. Standart ve TDKN ile güçlendirilmiş kompozit numune için dielektrik sabitinin, dielektrik kayıp faktörünün ve kayıp tanjantın frekansın fonksiyonu olarak değişimini tanımlamak için aşağıda verilen logaritmik bir fonksiyon tanımlanmıştır.

$$
y=a \cdot \ln (-b \cdot \ln x)
$$

Burada a ve b teorik fit için hesaplanan katsayılardır. Tablo 1'de kompozitlerin dielektrik sabitlerinin frekansla değişim eğrisine yapılan fit parametreleri ve modelin doğruluğunu test eden düzeltilmiş belirleme katsayıları $\left(\mathrm{R}^{2}\right)$ görülmektedir. Özellikle TDKN katkılı numuneler için elde edilen deneysel sonuçlarla logaritmik fit fonksiyonunun tutarlı olduğu ortaya konulmuştur.

Tablo 1. Dielektrik sabitinin frekans ile değişimi için yapılan fitteki parametreler.

\begin{tabular}{ccc}
\hline Katsayılar & Standart SMC & TDKN/SMC \\
\hline $\mathrm{a}$ & $-1,1$ & $-0,67$ \\
$\mathrm{~b}$ & $-9,8.10^{-4}$ & $-8,4.10^{-4}$ \\
$\mathrm{R}^{2}$ & 0.94 & 0,98 \\
\hline
\end{tabular}

Benzer şekilde Tablo 2 ve Tablo 3'de sirasıyla dielektrik kayıp faktörünün ve dielektrik dağılım faktörünün frekans ile değişimini teorik açıdan tanımlamak amacıyla yapılan fit değerleri mevcuttur. 
Her iki durumda da özellikle TDKN katkılı SMC numuneleri için yapılan teorik fitlerin deneysel sonuçlarla oldukça uyumlu olduğu görülmektedir. Böylece ölçüm yapılmayan diğer frekans değerlerinde de malzemelerin dielektrik davranışları öngörülebilir hale gelmiştir.

Tablo 2. Dielektrik kayıp faktörü-frekans değişimi için yapılan fitteki parametreler.

\begin{tabular}{ccc}
\hline Katsayılar & Standart SMC & TDKN/SMC \\
\hline $\mathrm{a}$ & $-0,69$ & $-0,98$ \\
$\mathrm{~b}$ & $-9,7.10^{-4}$ & $-6,6.10^{-4}$ \\
$\mathrm{R}^{2}$ & 0,87 & 0,98 \\
\hline
\end{tabular}

Tablo 3. Dielektrik kayıp faktörü-frekans değişimi için yapılan fitteki parametreler.

\begin{tabular}{ccc}
\hline Katsayılar & Standart SMC & TDKN/SMC \\
\hline $\mathrm{a}$ & $-0,0027$ & $-0,0041$ \\
$\mathrm{~b}$ & $-9,7.10^{-4}$ & $-6,6.10^{-4}$ \\
$\mathrm{R}^{2}$ & 0,77 & 0,97 \\
\hline
\end{tabular}

\section{Sonuç ve Öneriler}

Tek duvarlı karbon nanotüp gibi iletken doğalı parçacıklar ile uygun yoğunluklarda malzemeyi güçlendirme, bir kompozit malzemenin elektriksel özelliklerini kontrol edebilmenin yollarından biridir. Yapılan çalışma kapsamında standart ve TDKN ile güçlendirilmiş SMC numuneler hazırlanarak malzemelerin AC iletkenlikleri ve dielektrik özellikleri karşılaştırmalı olarak incelenmiştir.

Katkısız standart numune, frekans arttıkça doğrusal olarak artan AC iletkenliği ile tipik bir yalıtım davranışı sergilerken TDKN katkılı numune için kritik eşik oranının aşıldığı ve kompozit içinde baştanbaşa bir iletkenlik ağının oluştuğu gözlenmiştir. Diğer bir çıkarım da TDKN ilave edilen malzemenin AC iletkenliklerinin neredeyse frekanstan bağımsız olmasıdır.

Düşük frekanslarda numunelerin homojen olmayan içyapıları ve malzemede meydana gelen polarizasyonlar nedeniyle dielektrik sabiti ve dielektrik kayıpların yüksek olduğu, frekansın artmasıyla da polarizasyonların etkilerini kaybederek dielektrik sabitlerinin ve kayıplarının azalmasına yol açtığı ortaya konulmuştur. Özellikle TDKN katkılı numune için elde edilen sonuçların yapılan fitlerle de uyumlu olduğu gösterilmiştir.

Yapılan hesapların ve elde edilen bulguların ışığında TDKN katkılı malzemenin, yarıiletken malzemelerin kullanıldığı mikrodalga soğurucu malzeme tasarımı gibi uygulamalar için ideal olduğu ortaya konulmuştur. Benzer şekilde mikroelektronik alanında kapasitör gibi dielektrik özellik gerektiren uygulamalar için ise standart SMC malzemelerinin verimlilik açısından ön plana çıktığı görülmektedir. Sonraki çalışmalarda farklı katkılama konsantrasyonlarında bu malzemelerin iletkenlik ve dielektrik davranışları incelenebileceği gibi farklı sıcaklıklarda optimum çalışma şartları da belirlenebilir.

\section{Teşekkür}

Yazarlar çalışma sırasında kullanılan takviye malzemelerinin temininde ve numunelerin üretilmesindeki katkılarından dolayı Literatür Kimya’ya teşekkürlerini sunar.

\section{Yazarların Katkısı}

Yazarların makaleye olan katkıları eşit orandadır.

\section{Çıkar Çatışması Beyanı}

Yazarlar arasında herhangi bir çıkar çatışması bulunmamaktadır.

\section{Araştırma ve Yayın Etiği Beyanı}

Yapılan çalışmada araştırma ve yayın etiğine uyulmuştur. 


\section{Kaynaklar}

[1] Cooper C.A., Young R.J., Halsall M. 2001. Investigation into the deformation of carbon nanotubes and their composites through the use of Raman spectroscopy. Composites Part A, 32: 401-411.

[2] Chen W., Tao X., Liu Y. 2006. Carbon nanotube-reinforced polyurethane composite fibers. Composites Science and Technology, 66: 3029-3034.

[3] Shen Z., Bateman S., Wu D.Y., McMahon P., Olio M.D., Gotama J. 2009. The effects of carbon nanotubes on mechanical and thermal properties of woven glass fibre reinforced polyamide- 6 nanocomposites. Composites Science and Technology, 69: 239-244.

[4] Gnidakouong R.J.N., Kim M., Park H.W., Park Y.B., Jeong H.S., Jung Y.B., Ahn S.K., Han K., Park J.M. 2013. Electromagnetic interference shielding of composites consisting of a polyester matrix and carbon nanotube-coated fiber reinforcement. Composites Part A: Applied Science and Manufacturing, 50: 73-80.

[5] Ounaies Z., Park C., Wise K.E., Siochi E.J., Harrison J.S. 2003. Electrical properties of single wall carbon nanotube reinforced polyimide composites. Composites Science and Technology, 63: 1637-1646.

[6] Ahmad K., Pan W., Shi S.L. 2006. Electrical conductivity and dielectric properties of multiwalled carbon nanotube and alumina composites. Applied Physics Letters, 89: 133122-1-3.

[7] Pathania D., Singh D. 2009. A review on electrical properties of fiber reinforced polymer composites. International Journal of Theoretical \& Applied Sciences, 1: 34-37.

[8] Barrau S., Demont P., Peigney A., Laurent C., Lacabanne C. 2003. DC and AC conductivity of carbon nanotubes-polyepoxy composites. Macromolecules, 36: 5187-5194.

[9] Coleman J.N., Curran S., Dalton A.B., Davey A.P., McCarthy B., Blau W. 1998. Percolationdominated conductivity in a conjugated-polymer-carbon nanotube composite. Physical Review B-Condensed Matter Physics, 58: 7492-7495.

[10] Dang Z.M., Shehzad K., Zha J.W., Hussain T., Jun N., Bai J. 2011. On refining the relationship between aspect ratio and percolation threshold of practical carbon nanotubes/polymer nanocomposites. Japanese Journal of Applied Physics, 50: 080214.

[11] Yuan X. 2007. Experimental study of electrical conductivity of carbon nanotube, nanofiber buckypapers and their composites. MSc Thesis, Florida State University, Department of Industrial \& Manufacturing Engineering, U.S.

[12] Dyre J. Schroder T. 2000. Universality of ac conduction in disordered solids. Reviews of Modern Physics, 72: 873-892.

[13] Akram M., Javed A., Rizvi T.Z. 2005. Dielectric properties of industrial polymer composite materials. Turkish Journal Physics, 29: 355-362.

[14] Yang Q., Liu L., Hui D., Chipara M. 2016. Microstructure, electrical conductivity and microwave absorption properties of g-FeNi decorated carbon nanotube composites. Composites Part B, 87: 256-262.

[15] Pethrick R.A., Hayward D. 2002. Real time dielectric relaxation studies of dynamic polymeric systems. Progress in Polymer Science, 27: 1983-2017.

[16] Li Y., Cordovez M., Karbhari V.M. 2003. Dielectric and mechanical characterization of processing and moisture uptake effects in E-glass/epoxy composites. Composites Part B, 34: 383390.

[17] Chen Y., Wang S., Pan F., Zhang J. 2014. A numerical study on electrical percolation of polymermatrix composites with hybrid fillers of carbon nanotubes and carbon black. Journal of Nanomaterials, 2014: 1-9. 